\title{
A Compact Bandpass Microstrip Filter for Wireless Communication Applications
}

\author{
Kavitha Devi CS ${ }^{1}$,Umadevi $\mathbf{H}^{2}$,Jambunath Baligar ${ }^{3}$ \\ ${ }^{1}$ Assistant Professor, kavithasuresh.drait@gmail.com \\ ${ }^{2}$ Professor, umdevi.h@dr-ait.org \\ ${ }^{3}$ Associate Professor, jbaligar@gmail.com \\ Department of Electronics and Communication Engineering, \\ Dr. Ambedkar Institute of Technology, Bengaluru
}

Article History:Received:11 november 2020; Accepted: 27 December 2020; Published online: 05 April 2021

\begin{abstract}
A design of Compact Bandpass Microstrip Filter is proposed for wireless communication applications like Bluetooth, Wi-Fi, and 5G. Filter is constructed using parallel-coupled Microstrip lines to form 5th order filter of an inverted $\mathrm{C}$ structure. Ground slotted technique is used to enhance the bandwidth with dielectric constant of 9.9. The designed filter is simulated at a center frequency of $5.87 \mathrm{GHz}$ and bandwidth of $1.9 \mathrm{GHz}$ with an insertion loss of $-0.5 \mathrm{~dB}$, return loss of greater than $12 \mathrm{~dB}$. The proposed filter has a compact size, good increased bandwidth and cost-effective. These results are verified with the theoretically designed values and good agreements are recorded. Hence the proposed compact filter will provide a platform for designing and development of compact filters for the microwave regime.
\end{abstract}

Keywords: Bandwidth (BW), Compact Bandpass Microstrip filter, Low Pass Filter (LPF), compactness, Frequency.

\section{Introduction}

The Recent advancing technologies in modern wide-band radar and wireless communication applications demand high performance and compact bandpass filters. Due to the rapid growth of wireless communication systems leads for a requirement of bandpass filters for good selectivity, compactness, and economic, etc. [1-3]. Hence bandpass Microstrip filters are very commonly used due to its ease of fabrication using printed circuited technology which is very cost effective. In the field of handheld communication systems, the miniaturized size of the system or the device plays an important role in parallel with multi functionalities to be performed by the same device [4-5]. As the functionalities increase like multitasking by a single device its size may increase, but in new technologies incorporating many features and reducing the size of the particular device is the main concern like mobile phones. Therefore, much attention has been given to compact Bandpass Microstrip filters (CBMF). A Microstrip filter is designed to operate between the resistive source and the load impedance of $50 \mathrm{ohm}$ in most of the microwave systems [6-8]. These type of filters have a lot scope because of its compact size, low price, less weight, low insertion loss, wide stopband, and easy fabrication techniques. Used in many real-time applications of wireless communications in transceivers, for today's modern wireless communication systems [9-11]. Hence these Microstrip bandpass filters constitutes a group of electric filters, aimed to operate at frequencies ranging from megahertz to gigahertz frequency. This band of frequency is used in most of the broadcasting applications, TV, Bluetooth, 5G etc and its frequency spectrum ranges from 300 $\mathrm{kHz}$ to $300 \mathrm{GHz}$ called as microwave frequency range [12]. Due to low fabrication expenditure and miniaturization process, implementation of Microstrip filters using electronics and devices is thriving. In [13], a compact Microstrip bandpass filter is designed by coupling a loaded resistor micro strip lines to form a square open-loop resonator and to enhance its selectivity a square open-loop resonator is loaded with an open-circuited stub for realizing two transmission zeros in the upper stopband. [14] A new design method for a tunable bandpass filter with independently and more widely tunable transmission zeros. This paper in [15] filter structure gives a closer coupling, and performs better than the first coupled micro strip. In [16,17], a compact and highly-selective six-pole filter with a triple-mode resonator loaded with stub and patch is proposed. The designed six-pole filter is of two identical triple-mode resonators is designed.

II. Mathematical Analysis and Design:

Step1: Calculate the center frequency and angular frequencies: Centre Frequency $f_{0}$ :

$f_{0}=\sqrt{f_{1} f_{2}}=\sqrt{5} * 6.9=5.87 \mathrm{GHzAndBandwidth}(B W)=f_{2}-f_{1}=1.9 \mathrm{GHz}$

Angular Frequencies:

$\omega_{1}=2 \pi\left(f_{1}\right)=31.4 \mathrm{GHz}, \omega_{2}=2 \pi\left(f_{2}\right)=43.33 \mathrm{GHz}, \omega_{0}=2 \pi\left(f_{0}\right)=36.864 \mathrm{GHz}$

*Corresponding author: Kavitha Devi CS

Assistant Professor, kavithasuresh.drait@gmail.com

Department of Electronics and Communication Engineering,

Dr. Ambedkar Institute of Technology, Bengaluru 
Relative angular difference:

$$
\Delta=\omega_{2}-\omega_{1} / \omega_{0} \quad=0.324
$$

Step2: Design of LPF prototype using Coefficients for the maximally flat LPF for $\mathrm{N}=5$

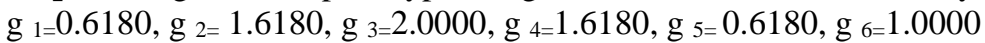

The Coefficients for maximally flat LPF from $g_{1}$ to $g_{6}$ are taken from the Butterworth table because our work $\mathrm{N}=5$, From these values of $\mathrm{g}$ construct the LPF prototype circuit as shown in Fig 1 below:

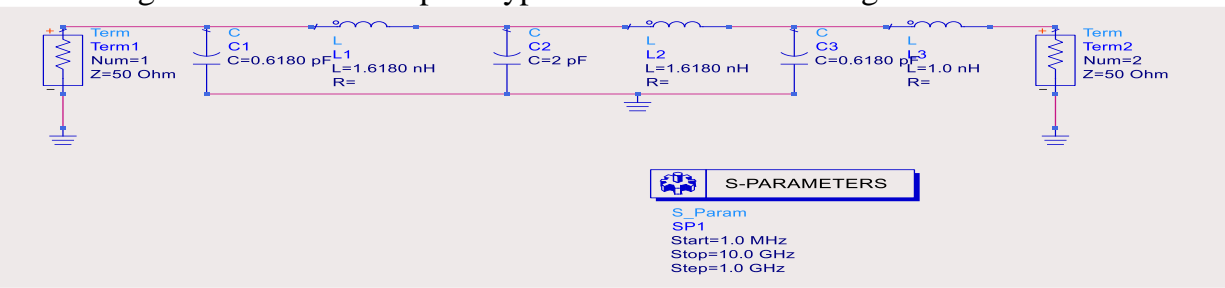

Fig 1: Initial low pass prototype of $5^{\text {th }}$ order

Step 3: Conversion of low pass prototype to bandpass filter values and calculations of $\mathrm{L}$ and $\mathrm{C}$ as follows

For capacitor: $C_{1}=\frac{c}{\omega_{0} \Delta}, L_{2}=\frac{L}{\omega_{0} \Delta}$, For Inductor: $C_{2}=\frac{\Delta}{\omega_{0} c}, L_{2}=\frac{L}{\omega_{0} \Delta}$

\begin{tabular}{|l|c|}
\hline $\mathrm{g}$ & Values of $\mathrm{L}$ and $\mathrm{C}$ \\
\hline $\mathrm{g}_{1}, \mathrm{~g}_{5}$ & $\mathrm{C}_{1}=51.7 \mathrm{pF}, \mathrm{L}_{1}=0.0142 \mathrm{nH}$ \\
\hline $\mathrm{g}_{2}, \mathrm{~g}_{4}$ & $\mathrm{~L}_{2}=0.1354 \mathrm{nH}, \mathrm{C}_{2}=5.432 \mathrm{pF}$ \\
\hline $\mathrm{g}_{3}$ & $\mathrm{C}_{3}=167.4 \mathrm{pF}, \mathrm{L}_{3}=0.004395 \mathrm{nH}$ \\
\hline $\mathrm{g}_{6}$ & $\mathrm{~L}_{6}=0.08372 \mathrm{nH}, \mathrm{C}_{6}=8.789 \mathrm{pF}$ \\
\hline
\end{tabular}

Table 2: Values of L and C for Schematic Design

Here in Table 2 the $\mathrm{g}_{1}$ to $\mathrm{g}_{6}$ represents capacitor and inductance values of filter for the corresponding $\mathrm{g}$ values. In band pass filter $\mathrm{g}_{0}=\mathrm{g}_{6}=1, \mathrm{~g}_{1}=\mathrm{g}_{5}$ and $\mathrm{g}_{2}=\mathrm{g}_{5}$ to form a symmetrical network and its respective capacitor and inductor values are calculated using the equ. (5)

\section{Simulation results and discussions:}

1. Schematic circuit for Bandpass filter design using lumped components:
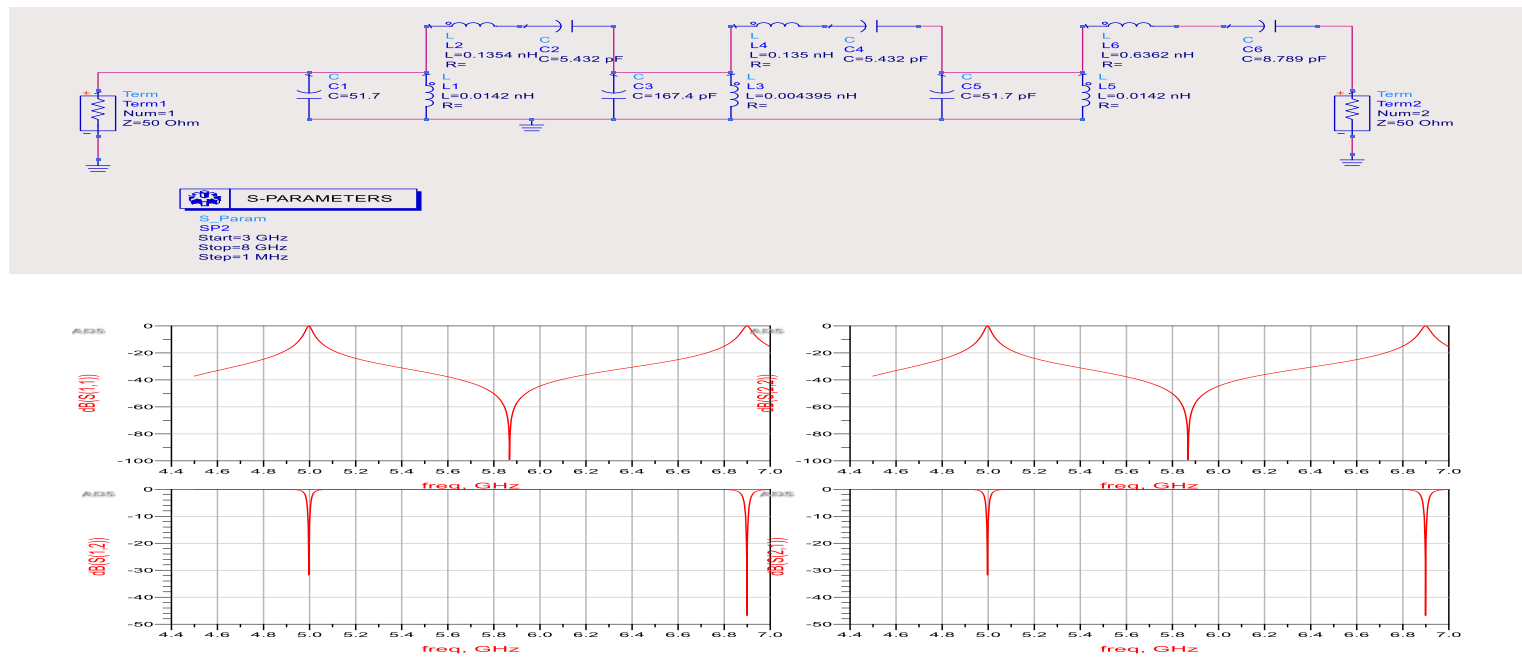

Figure 2: Schematic Bandpass filter design using lumped components and its corresponding simulations results By using table 2 the Schematic Bandpass filter is constructed and its corresponding simulation results Fig 2 are verified with the design value of $1.9 \mathrm{GHz}$ as shown in Eqs (1). Calculation of Even and Odd mode impedance (Ze\& Z0) for Microstrip line circuit is shown in Eqs [5] and tabulated in table 2

$Z 0 J 1=\sqrt{\pi \Delta / 2 g 1}, \mathrm{Z} 0 \mathrm{e} 1=\mathrm{Z} 0\left[1+\mathrm{Z} 0 \mathrm{~J} 1+(\mathrm{Z} 0 \mathrm{~J} 1)^{2}\right], \mathrm{Z} 0 \mathrm{o} 1=\mathrm{Z} 0\left[1-\mathrm{Z} 0 \mathrm{~J} 1+(\mathrm{Z} 0 \mathrm{~J} 1)^{2}\right.$
$Z 0 J 2=\pi \Delta / 2 \sqrt{g 1 g 2}, \mathrm{Z} 0 \mathrm{e} 2=\mathrm{Z} 0\left[1+\mathrm{Z} 0 \mathrm{~J} 2+(\mathrm{Z} 0 \mathrm{~J} 2)^{2}\right], \mathrm{Z} 0 \mathrm{o} 2=\mathrm{Z} 0\left[1-\mathrm{Z} 0 \mathrm{~J} 2+(\mathrm{Z} 0 \mathrm{~J} 2)^{2}\right]$ 


$$
Z 0 J 3=\pi \Delta / 2 \sqrt{g 2 g 3}, \mathrm{Z} 0 \mathrm{e} 3=\mathrm{Z} 0\left[1+\mathrm{Z} 0 \mathrm{~J} 3+(\mathrm{Z} 0 \mathrm{~J} 3)^{2}\right], \mathrm{Z0o} 3=\mathrm{Z} 0\left[1-\mathrm{Z} 0 \mathrm{~J} 3+(\mathrm{Z} 0 \mathrm{~J} 3)^{2}\right]
$$

\begin{tabular}{|c|c|c|}
\hline Order of filter & $Z 0_{e}(\boldsymbol{\Omega})$ & $Z 00(\boldsymbol{\Omega})$ \\
\hline 0 & 136.524 & 45.730 \\
\hline 1 & 88.375 & 37.505 \\
\hline 2 & 68.140 & 39.860 \\
\hline 3 & 68.140 & 39.860 \\
\hline 4 & 88.375 & 37.505 \\
\hline 5 & 136.524 & 45.730 \\
\hline
\end{tabular}

Table 3: odd and even impedance

The Selection of actual Microstrip lines is done using Line Clac in ADS, Substitute the values of Z0o, Z0e as per table 3 in LineClac. Note down the values of Length (L), Width (W) and spacing(S) between the Microstrip line in mil respectively and tabulate the values for all the lines as shown in Table 4.

\begin{tabular}{|c|c|c|c|}
\hline Order of the filter & W(mil) & S(mil) & L(mil) \\
\hline $\mathrm{L}_{1}$ & 6.7842 & 5.7513 & 208.3094 \\
\hline $\mathrm{L}_{2}$ & 21.0640 & 8.4331 & 200.5882 \\
\hline $\mathrm{L}_{3}$ & 31.6245 & 19.4311 & 195.9032 \\
\hline $\mathrm{L}_{4}$ & 31.6245 & 19.4311 & 195.9032 \\
\hline $\mathrm{L}_{5}$ & 21.0640 & 8.4331 & 200.5882 \\
\hline $\mathrm{L}_{6}$ & 6.7842 & 5.7513 & 208.3094 \\
\hline
\end{tabular}

Table 4: Tabulation of W, S and L in mil

2. Equivalent microstrip line schematic circuit using table 4

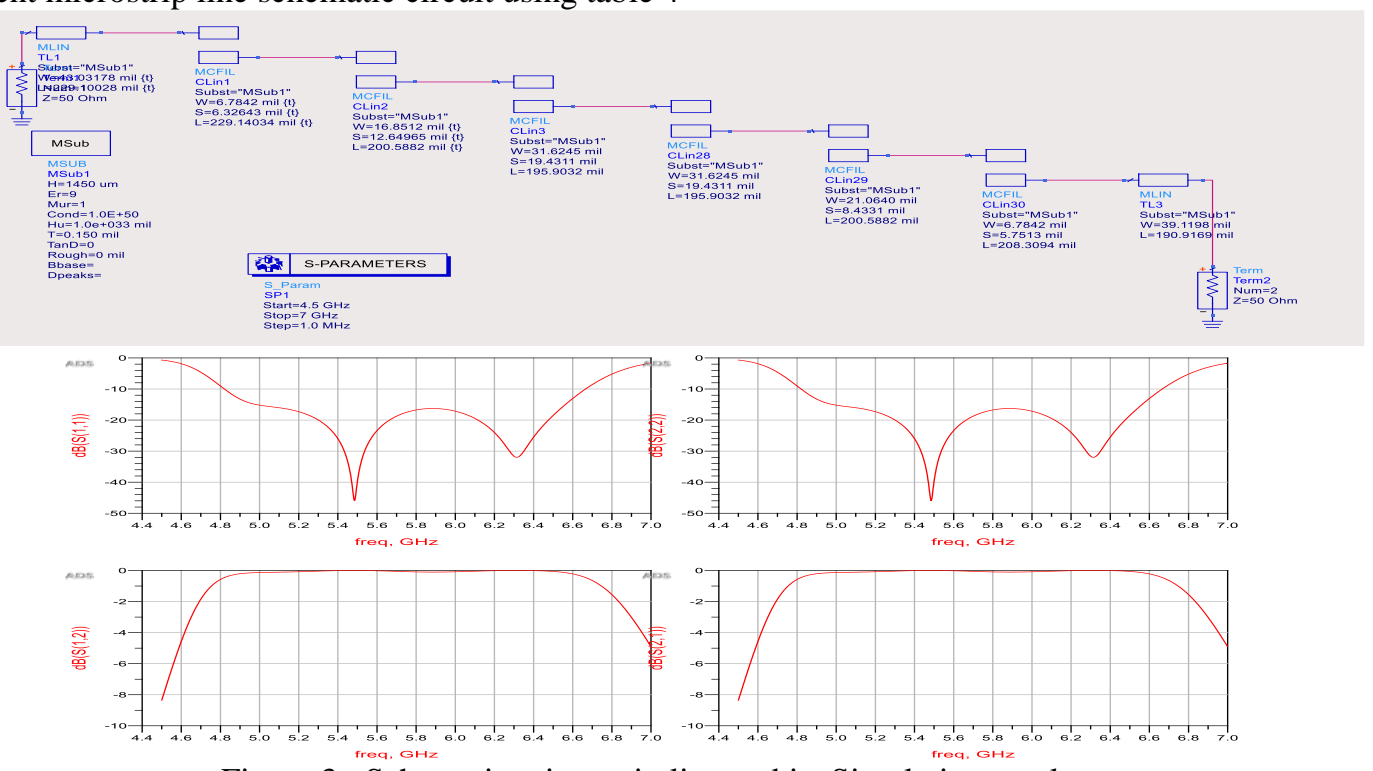

Figure 3: Schematic microstrip line and its Simulation results

Bandpass Filter using Microstrip lines and its simulation results are shown in Fig 3 and verified with the designed value of bandwidth as shown in the Eqs (1)

3. Compact Bandpass Microstrip Filter 


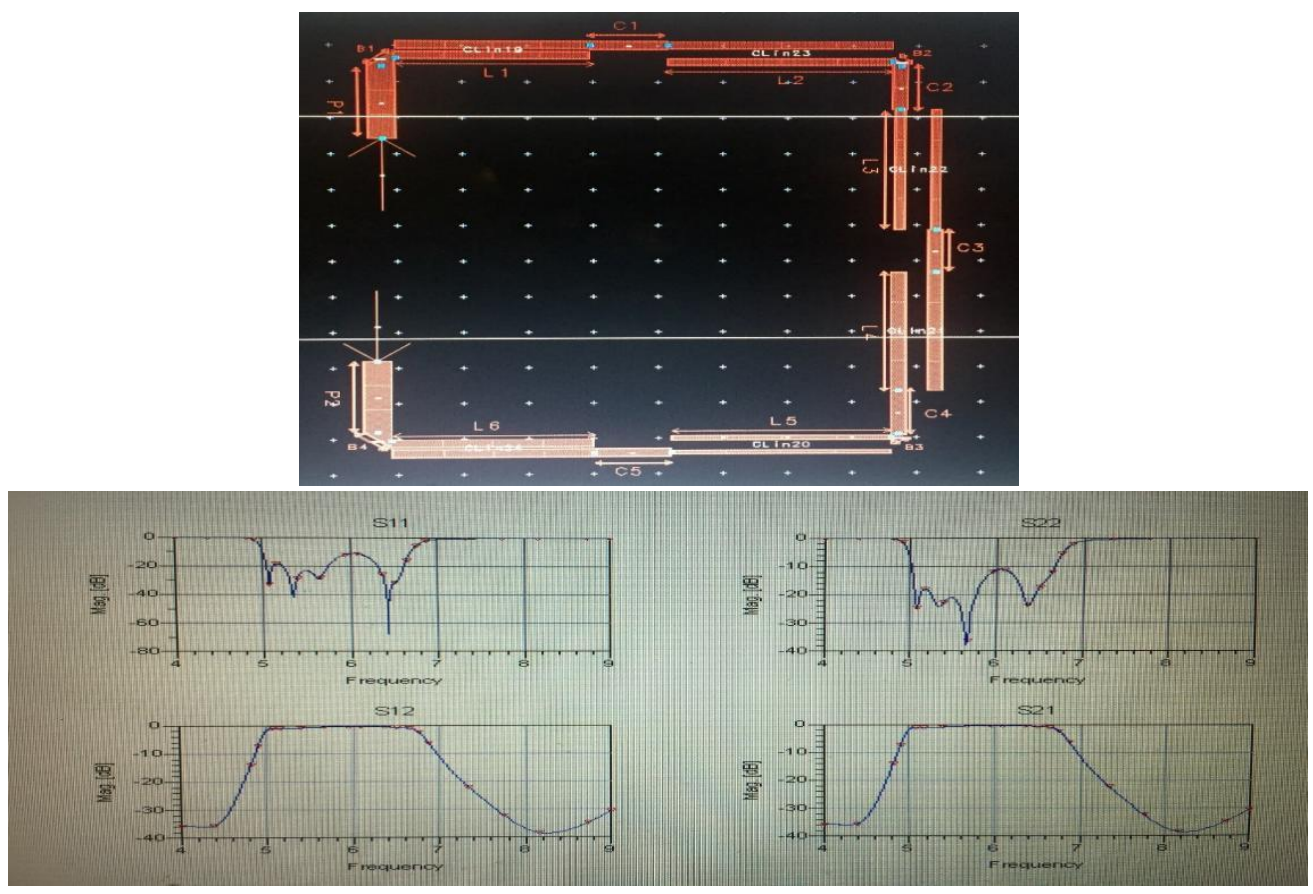

Figure 4: Compact Bandpass Microstrip Filter and its Simulation results

A Compact Bandpass Microstrip Filter is a 5th order Filter with Folded inverted C structure using Microstrip lines as shown in the Fig 4 by doing so its size is reduced to almost to $1 / 3 \mathrm{rd}$ and bandwidth is also achieved.

\begin{tabular}{|l|l|c|}
\hline \multicolumn{1}{|c|}{ Type of Filter } & \multicolumn{1}{|c|}{ Size } & BW \\
\hline Hairpin Filter[1] & Width=27.7156mm, Height $=8.5204 \mathrm{~mm}$ & $0.4 \mathrm{GHz}$ \\
\hline Proposed Filter & Width=7 mm, Height=10mm & $1.9 \mathrm{GHz}$ \\
\hline
\end{tabular}

Table 5: Comparative study

The proposed filter is very good in two parameters compactness and bandwidth as shown in table 5

\section{Conclusion:}

As the frequency increases the reactance of the lumped components (Inductors and Capacitors) varies and it's not constant hence size of the filter will be very large. Therefore it is not possible to maintain the proper characteristics of the filter at higher frequencies and difficulty to fabricate the large-size structure. Therefore, to overcome this difficulty, it's better to use Microstrip Line Filters to reduce the size. Hence, a Compact Bandpass Microstrip Filters presented in this paper using Keysight's ADS software with the operating frequency at $5.87 \mathrm{GHz}$. The design has been performed using parallel-coupled Microstrip transmission line structures with good compactness and BW of $1.9 \mathrm{GHz}$, minimum insertion loss of $-0.5 \mathrm{~dB}$. This filter is much useful for wireless communication applications like Bluetooth, WiFi, and 5G.

\section{References:}

Devi, K., Umadevi, H. and Baligar, J.S., 2019, June. Designing of Reconfigurable Compact Bandpass Microstrip Filter. In 2019 3rd International conference on Electronics, Communication and Aerospace Technology (ICECA) (pp. 726-730). IEEE.

Devi, K. and Umadevi, J.B., 2019. Reconfigurable Compact Bandpass Microstrip Filter of Bandwidth 1.54 GHz. American Journal of Networks and Communications, 8(2), pp.59-63.

Al-Areqi, N.N., Seman, N. and Rahman, T.A., 2017. Design of Microstrip Parallel-Coupled Line Band Pass Filters for the Application in Fifth Generation Wireless Communication. Journal of Telecommunication, Electronic and Computer Engineering (JTEC), 9(2-7), pp.19-23.

Avinash, K.G. and Rao, I.S., 2015, December. Design of compact meandered dual mode wideband microstrip bandpass filter using tuning stubs. In 2015 International Conference on Microwave and Photonics (ICMAP) (pp. 1-2). IEEE.

Sahu, B., Meshram, M.K., Singh, S.P. and Tripathi, P., 2015, December. Simulation study of modified compact microstrip interdigital bandpass filter with wide stopband for L-band applications. In 2015 IEEE MTT-S International Microwave and RF Conference (IMaRC) (pp. 409-411). IEEE.

Annapurna Das, Sisir K Das Mar 5, 2018 - Microwave Engineering. TMH Publication 2nd Edition 
Ludwig, Reinhold, Bogdanov, Gene, April 19, 2008, RF Circuit Design: Theory \& Applications (2nd Edition)... For anyone interested in learning more about RF circuit design. ... Hardcover: 720 pages; Publisher: Pearson; 2 edition (); Language

Dabhi, V.M. and Dwivedi, V.V., 2016, October. Parallel coupled microstrip bandpass filter designed and modeled at $2 \mathrm{GHz}$. In 2016 International Conference on Signal Processing, Communication, Power and Embedded System (SCOPES) (pp. 461-466). IEEE.

Arnedo, I., Arregui, I., Lujambio, A., Chudzik, M., Laso, M.A. and Lopetegi, T., 2012. Synthesis of microwave filters by inverse scattering using a closed-form expression valid for rational frequency responses. IEEE transactions on microwave theory and techniques, 60(5), pp.1244-1257.

Chaudhari, N.P., Kumar, A. and Verma, A.K., 2012, January. Transverse Resonance Phenomena Based Low Pass Filter. In 2012 Second International Conference on Advanced Computing \& Communication Technologies (pp. 505-508). IEEE.

Kumar, A., Chaudhari, N.P. and Verma, A.K., 2012, January. Constant-k and m-derived composite low pass filter using defected ground structure. In 2012 Second International Conference on Advanced Computing \& Communication Technologies (pp. 454-456). IEEE.

Huang, X. and Wu, K.L., 2012. A broadband and via less vertical micro strip-to-micro strip transition. IEEE Transactions on microwave theory and techniques, 60(4), pp.938-944.

Wang, Zhongbao, Zheng Fu, Chengze Li, Shao-Jun Fang, and Hongmei Liu. "A Compact Negative-GroupDelay Microstrip Bandpass Filter." Progress In Electromagnetics Research 90 (2020): 45-51.

Cheng, Fei, XuanTan Li, Ping Lu, and Kama Huang. "A micro strip bandpass filter with 2 independently tunable transmission zeros." Microwave and Optical Technology Letters 62, no. 5 (2020): 1951-1956.

Xie, HaoWei, Kang Zhou, ChunXia Zhou, and Wen Wu. "Analysis of four stage stepped impedance resonators and their application to quad band micro strip bandpass filter." International Journal of RF and Microwave Computer Aided Engineering 30, no. 4 (2020): e22116.

Chen, Chi-Feng. 'Design of a Microstrip Three-State Switchable and Fully Tunable Bandpass Filter With an Extra-Wide Frequency Tuning Range.” IEEE Access 8 (2020): 66438-66447.

Luo, Cong, Sai-Wai Wong, Jing-Yu Lin, Yang Yang, Yin Li, Xu-Zhou Yu, Lin-Ping Feng, Zhi-Hong Tu, and Lei Zhu. "Quasi-reflection less micro strip bandpass filters using band stop filter for out-of-band improvement.” IEEE Transactions on Circuits and Systems II: Express Briefs (2019). 